\title{
神农架常绿落叶阔叶混交林调落物动态及影响因素
}

\author{
刘 璐 ${ }^{1,2}$ 赵常明 ${ }^{1}$ 徐文婷 ${ }^{1}$ 申国珍 ${ }^{1}$ 谢宗强 ${ }^{1,2 *}$ \\ ${ }^{1}$ 中国科学院植物研究所植被与环境变化国家重点实验室, 北京 $100093 ;{ }^{2}$ 中国科学院大学, 北京 100049
}

\begin{abstract}
摘 要 调落物是陆地生态系统的重要组成部分, 调落物动态特征可以反映出生态系统的存在状况以及环境对植被的影响 作用。为探究北亚热带常绿落叶阔叶混交林调落物产量及现存量的动态及其影响因素, 该研究观测了神农架地区一处典型植 被2009-2015年的调落物产量及现存量, 据此分析其动态特征及其与气象因素的关系。研究结果表明: 该森林调落物平均年产 量及现存量分别为 $5.94 \mathrm{t} \cdot \mathrm{hm}^{-2}$ 和 $10.46 \mathrm{t} \cdot \mathrm{hm}^{-2}, 2009$ 至 2014 年均无明显年际变化趋势, 但在 2015 年均显著降低, 且当年倒春寒 天数显著高于其他年份; 季节动态变化呈现双峰型, 峰值分别出现在 $3-5$ 月和 10 月; 调落物月产量与当月的前第 $1-4$ 个月的月 平均气温正相关，与当月的前第8-10个月的月平均气温负相关，且与当月的前第6-7及第10个月的月平均相对湿度负相关; 调落物产量季节性指数平均值为 0.032 , 与年平均气温显著正相关。可见, 长时间倒春寒现象会显著影响调落物年产量及现存 量, 月平均气温和相对湿度对调落物产量季节动态的影响有明显的滞后性, 且年平均气温对北亚热带主要森林类型的凋落物 产量季节性指数有显著影响。
\end{abstract}

关键词 调落物产量; 调落物现存量; 滞后性; 季节性指数; 北亚热带

刘璐, 赵常明, 徐文婷, 申国珍, 谢宗强 (2018). 神农架常绿落叶阔叶混交林调落物动态及影响因素. 植物生态学报, 42, 619-628. DOI: $10.17521 /$ cjpe.2018.0052

\section{Litter dynamics of evergreen deciduous broad-leaved mixed forests and its influential factors in Shennongjia, China}

LIU Lu ${ }^{1,2}$, ZHAO Chang-Ming ${ }^{1}$, XU Wen-Ting ${ }^{1}$, SHEN Guo-Zhen ${ }^{1}$, and XIE Zong-Qiang ${ }^{1,2 *}$

${ }^{1}$ State Key Laboratory of Vegetation and Environmental Change, Institute of Botany, Chinese Academy of Sciences, Beijing 100093, China; and ${ }^{2}$ University of Chinese Academy of Sciences, Beijing 100049, China

\begin{abstract}
Aims Litter is an important component of terrestrial ecosystems. The dynamics of litter can reflect the stage of terrestrial ecosystems and the impact of environment on vegetation. Our objective was to explore the dynamics of litter production and standing crop in evergreen deciduous broad-leaved mixed forests and the underlying factors.

Methods During 2009-2015, we observed the litter production and the standing crop of a typical vegetation at Shennongjia, Hubei Province and analyzed their dynamics and relationships with meteorological factors.

Important findings 1) The results showed that the average annual litter production and standing crop were $5.94 \mathrm{t} \cdot \mathrm{hm}^{-2}$ and $10.46 \mathrm{t} \cdot \mathrm{hm}^{-2}$, respectively. Additionally, there was no remarkable inter-annual changing trend between 2009 and 2014, nevertheless a significant lower value appeared in 2015 with much more days of late spring coldness. 2) The seasonal dynamics presented double peaks, in March to May and October separately. 3) The monthly litter production was positively correlated with the monthly average air temperature of the previous $1-4$ months, but negatively correlated with that in the 8th, 9th and 10th months before the month. In addition, it was negatively associated with the monthly average relative humidity of the 6th, 7th and 10th months before the month. 4) The average seasonality index of litter production was 0.032 , which was strongly positively correlated with the annual average air temperature. We concluded that the phenomenon of long-term late spring coldness will affect annual litter production and standing crop significantly. The monthly average air temperature and relative humidity had significant lag effect on the seasonal dynamics of litter production, and the annual average air temperature had positive influence on the seasonality index of litter production in the major forest types in north subtropics.
\end{abstract}

收稿日期Received: 2018-03-01 接受日期Accepted: 2018-05-12

基金项目: 中国科学院前沿科学重点研究项目(QYZDY-SSW-SMC011)。Supported by the Frontier Science Key Research Project of Chinese Academy of Sciences (QYZDY-SSW-SMC011).

* 通信作者Corresponding author (xie@ibcas.ac.cn) 
Key words litter production; litter standing crop; lag effect; seasonality index; north subtropics

Liu L, Zhao CM, Xu WT, Shen GZ, Xie ZQ (2018). Litter dynamics of evergreen deciduous broad-leaved mixed forests and its influential factors in Shennongjia, China. Chinese Journal of Plant Ecology, 42, 619-628. DOI: 10.17521/cjpe.2018.0052

调落物也称枯落物, 是指植物地上部分产生并 归还到地表的所有有机物质的总称，是连接陆地生 态系统地下和地上生态过程的关键媒介(Facelli \& Pickett, 1991)。调落物在维持土壤肥力、促进生态 系统正常的物质循环和养分平衡方面起重要作用。 森林是全球陆地生态系统的重要组成部分。森林调 落物产量和调落进程主要受到气候和森林状况的影 响，因此森林调落物时间动态可以反映出森林生态 系统的重要过程以及环境对植被的影响作用(郑征 等, 2005)。植物调落时间及调落物季节动态还会直 接影响短时间内的土壤呼吸和碳收支 (Janssens \& Pilegaard, 2003; DeForest et al., 2009)。

总的来说，调落物产量的时间动态由多种外部 因素以及物种生理特征所决定。长期定位观测发现 群落特征是影响调落物年际动态的主要因素(官丽 莉等, 2004; Li et al., 2010; Aguilos et al., 2012)。降水 量及温度是影响调落物季节动态的主要因素(Sanches et al., 2008; 张新平等, 2008; 武启寒等, 2017); 但多数研究在模型构建中并没有将与气象相关的时 间因素考虑进去, 忽视了特定气象因素对调落物季 节动态的滞后影响。因此本研究在季节动态方面主 要针对气象因素对森林调落物动态的滞后影响开展 相关研究。

常绿落叶阔叶混交林是我国北亚热带地区最具 代表性的植被类型, 是结构最复杂、生物多样性最 丰富的地带性植被类型, 对维护区域生态环境和全 球碳平衡等都具有极重要的作用(黄永涛, 2016)。神 农架地跨中亚热带和北亚热带, 青藏高原的隆起使 该区域保存有全球同纬度最为完好的地带性常绿落 叶阔叶混交林带, 且其优势树种不同于同纬度分布 的其他同类型森林(马明哲等, 2017)。神农架常绿落 叶阔叶混交林带以壳斗科树种为主, 其中落叶树种 主要为栎属(Quercus)和水青冈属(Fagus)等, 常绿树 种则以青冈属 (Cyclobalanopsis)、雉栗属 (Castanopsis)和柯属(Lithocarpus)等为主。因此, 在神农 架地区开展的调落物动态研究对了解北亚热带典型 植被的存在状况及发展趋势有重要意义。

本研究通过对神农架常绿落叶阔叶混交林 7 年 间的调落物产量及现存量的观测数据的分析, 拟解
决以下科学问题: 北亚热带地区典型植被常绿落叶 阔叶混交林的调落物动态特征是怎样的? 其与气象 因素、森林状况之间有怎样的关系?

\section{1 研究方法}

\section{1 研究地点}

研究地点位于湖北省西部神农架南坡, 为神农 架站常绿落叶阔叶混交林综合观测场土壤生物采样 地 1 号永久性样地, 地理位置为 $31.33^{\circ} \mathrm{N}, 110.49^{\circ} \mathrm{E}$, 海拔 $1700 \mathrm{~m}$ 。该区属于秦巴山地常绿落叶阔叶天然 林生态区，年平均气温 $10.6{ }^{\circ} \mathrm{C}$ ，年降水量 1306-1 $722 \mathrm{~mm}$ 。土壤类型为山地黄棕壤, $\mathrm{pH}$ 值 5.77 , 土层厚度为 $100 \mathrm{~cm}$, 其中 $0-20 \mathrm{~cm}$ 为沙壤, 颜色褐色; 20-50 cm 为过渡层, 颜色浅黄; 50-80 cm 为黄胶土, 黄色; $80 \mathrm{~cm}$ 以下为白浆岩, 灰白色。土壤母质主要 为石灰岩和页岩。样地坡度 $40^{\circ}$, 坡向 NW $5^{\circ}$ 。植物 群落高达 $25 \mathrm{~m}$, 群落结构由乔木层、灌木层、草本 层以及层间植物组成，其中乔木层可分为 3 个亚层 (I、II、III)，群落盖度约 $90 \%$ 。乔木层中的乔木I亚 层主要由米心水青冈(Fagus engleriana)、多脉青冈 (Cyclobalanopsis multinervis)、曼青冈(Cyclobalanopsis oxyodon)、湖北我耳枥(Carpinus hupeana)、 枹栋(Quercus serrata)和灯台树(Bothrocaryum controversum)等乔木树种组成，高度15-25 m, 盖度约 $40 \%$; 乔木II层以多种青冈(Cyclobalanopsis spp.)、粉 白杜鹃(Rhododendron hypoglaucum)、巴东栎(Quercus engleriana)、四照花(Cornus kousa ssp. Chine$n$ sis)、三桠乌药(Lindera obtusiloba)、山白树(Sinowilsonia henryi)、多种枫树(Acer spp.)、石灰花楸 (Sorbus folgneri)等组成，高度 8-15 m, 盖度约60\%; 乔木III层主要由川钓樟 (Lindera pulcherrima var. hemsleyana)、猫儿刺(Ilex pernyi)、宜昌木姜子(Litsea ichangensis)、短柱柃 (Eurya brevistyla)、香叶子 (Lindera fragrans)以及多种青冈的小树等组成，高 度4-6 m, 盖度约 35\%; 灌木层主要由箭竹(Fargesia spathacea)、箬竹(Indocalamus tessellatus)以及乔木 的幼树组成, 高度 $1-4 \mathrm{~m}$, 盖度约 $60 \%$; 草本层主要 由莎草科的多种薹草(Carex spp.)、禾本科的野青茅 (Deyeuxia spp.) 和多种葓类等植物组成, 高度 $0.5 \mathrm{~m}$ 
左右，盖度约 $15 \%$ 。层间植物包括五月瓜藤(Holboellia angustifolia)、多种猕猴桃(Actinidia spp.)、多 种拢荰(Smilax spp.)、多种铁线莲(Clematis spp.)等藤 本植物, 高度从林下的 $0.5 \mathrm{~m}$ 到林冠的 $20 \mathrm{~m}$ 不等。枯 枝落叶层厚度为 $5-10 \mathrm{~cm}$ 。该森林生态系统为成熟林, 正处于顶极演替阶段。样地位于自然保护区的中心 地带, 人类活动很少, 影响程度较轻, 较好地保持 了自然状态。

\section{2 调落物的收集与整理}

主观测场的I级样方面积为 $100 \mathrm{~m} \times 100 \mathrm{~m}$ 。在 I 级样方内, 进一步划分成了 100 个II级样方 $(10 \mathrm{~m} \times$ $10 \mathrm{~m})$, 随机选择 13 个II级样方, 并在每个样方内选 取一个 $1 \mathrm{~m} \times 1 \mathrm{~m}$ 的小样方, 在森林地面或离地面一 定距离水平放置一个面积为 $1 \mathrm{~m}^{2}$ 的方框式收集器, 收集器底部采用尼龙网眼窗纱, 四周用木框固定。 自2008年10月至2015年12月, 每月末收回林内收集 器中的调落物, 每框中的调落物分别收集。将每次 回收的调落物按枝、叶、花果(繁殖器官)、树皮、 苔藓地衣、杂物等分开, 在 $65{ }^{\circ} \mathrm{C}$ 下烘干至恒质量并 称量记录, 将此用于调落物产量的年际动态及季节 动态研究。为避免影响生态系统内物质循环平衡, 收集的样品烘干称质量后如无其他用途则放回样方 原位置。自2009年至2015年, 每年7月下旬(植物生 长旺期, 调落物现存量最少)在调落物收集框邻近 地表选择一处 $1 \mathrm{~m} \times 1 \mathrm{~m}$ 的样方, 收集其中全部调落 物, 处理方法同上, 将此用于调落物现存量的年际 动态研究。

\section{3 气象数据的获取}

气象数据来自综合观测场附近的神农架森林生 态系统国家野外科学观测研究站2008-2015年观测 记录的各项气象指标数据, 包括日平均气温、月平 均气温、月最高气温、月最低气温、月降水量、月 平均风速、月平均相对湿度、月平均辐射以及月日 照时间。

\section{4 数据分析}

统计分析法主要包括利用主成分分析(PCA)篮 选气候变量, 并采用KMO (Kaiser-Meyer-Olkin)检 验判断分析结果是否可用(Caritat et al., 2006), KMO 范围在 $0-1$ 之间, KMO $>0.5$ 代表变量之间相关性显 著, 主成分分析结果可信。利用向量代数模型计算 调落物季节性指数(Parsons et al., 2014)。计算公式 如下:

$$
\begin{aligned}
& m_{x}=\frac{1}{12} \sum L_{m o n} \cos (30 \times i) \\
& m_{y}=\frac{1}{12} \sum L_{m o n} \sin (30 \times i) \\
& m=\left(m_{x}, m_{y}\right) \\
& S L=\|m\| / L
\end{aligned}
$$

其中 $i$ 代表月份 $-1, L_{\mathrm{mon}}$ 代表当月的凋落物产量, $L$ 代 表全年的凋落物产量, $S L$ 代表季节性指数。SL衡量 的是凋落物产量在一年中不同月份的分配情况，其 范围在0-1之间, 越趋近于 0 代表调落物产量在一年 中不同月份之间越接近于平均分布，越趋近于 1 代 表其越接近集中分布于 1 个月内。凋落物动态变化以 及调落物季节性的影响因素分别采用互相关分析 (CCF) 以及相关性分析，显著性水平设为 0.05 。所有 统计分析采用 R软件(http://www.r-project. org)实现。

\section{2 研究结果}

\section{1 调落物产量年际动态}

7年监测结果表明, 调落物总产量平均值为 5.94 $\mathrm{t} \cdot \mathrm{hm}^{-2} \cdot \mathrm{a}^{-1}, 2009-2014$ 年无明显的年际变化趋势, 2015年显著降低(图1)。调落物各组分含量 $\left(\mathrm{t} \cdot \mathrm{hm}^{-2} \cdot \mathrm{a}^{-1}\right)$ 表现为叶(2.56-5.65) > 枝 $(0.49-1.89)>$ 繁殖器官 $(0.08-0.68)>$ 杂物 $(0.16-0.36)>$ 树皮 $(0.10-0.25)>$ 苔 藓地衣 $(0.01-0.05)$, 分别占调落物总量的 $71.5 \%$ 、 $17.4 \% 、 5.1 \% 、 3.3 \% 、 2.5 \%$ 和 $0.3 \%$ 。叶是调落物的 主要成分, 其年际动态与调落总量的年际动态一致;

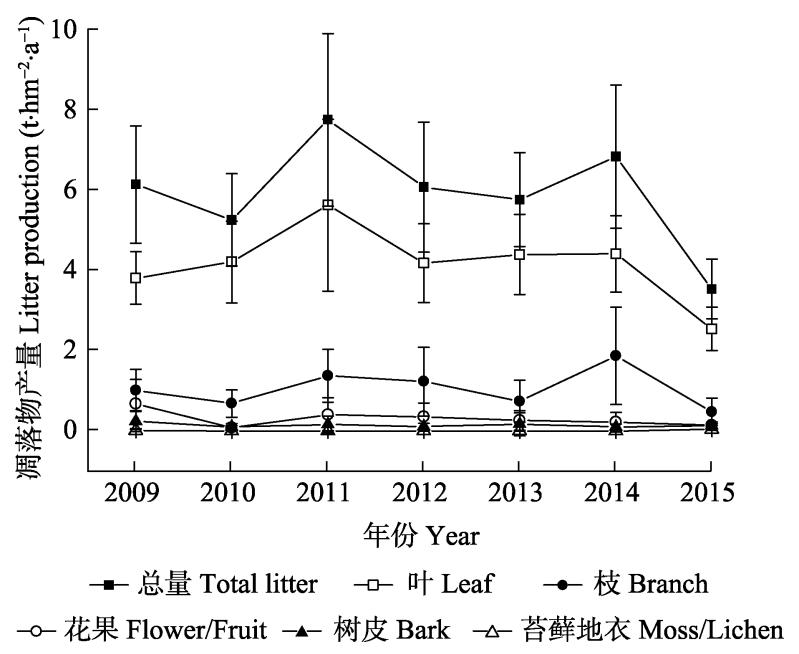

图12009-2015年调落物产量年际动态变化(平均值土标准 偏差)。每一个数据点是 13 个调落物收集框的年平均值。

Fig. 1 The dynamics of annual litter production from 2009 to 2015 (mean $\pm S D$ ). Every point is the average annual value of the mass in 13 litter traps. 
枝的调落量年际动态较为稳定, 仅在2014年产量较 高; 繁殖器官、树皮及苔蘚地衣无明显变化趋势。

Pearson相关分析结果显示, 调落物年际总产量 及各组分产量与气象因素之间并无明显的相关关系 $(n=7, p>0.05)$ 。凋落叶产量在2015年显著低于其 他年份，同年4月份(即树木生叶期间)发生了长达 12 天的倒春寒现象，显著长于其他年份(图2)。

\section{2 调落物产量的季节动态}

年内调落总产量表现为具有一定时间规律的双 峰曲线波动(图3)，10月份是明显的调落高峰期，仅 一个月内的调落物就占全年调落物产量的 $34 \% ; 3-5$ 月为次高峰期, 共占全部调落物产量的 $20 \%$ 。调落 叶产量的年内动态与总量的年内动态基本一致, 表 现为双峰曲线波动, 分别在 4-5月及 10 月份出现调落 高峰，对应的调落量分别占调落总量的 $14 \%$ 及 $42 \%$ 。 枝及繁殖器官年内调落产量无稳定的时间规律。

气象变量之间相关性显著 $(\mathrm{KMO}=0.71)$ 。主成 分分析结果显示第一主成分与第二主成分共解释了
$75.1 \%$ 的方差(图4)。第一主成分解释了 $52.1 \%$ 的方差, 其中温度相关变量与降水量、辐射量以及日照时间 具有显著的相关关系，如月平均气温与月平均辐射 之间的相关系数 $r=0.82(n=96, p<0.001)$; 第二主

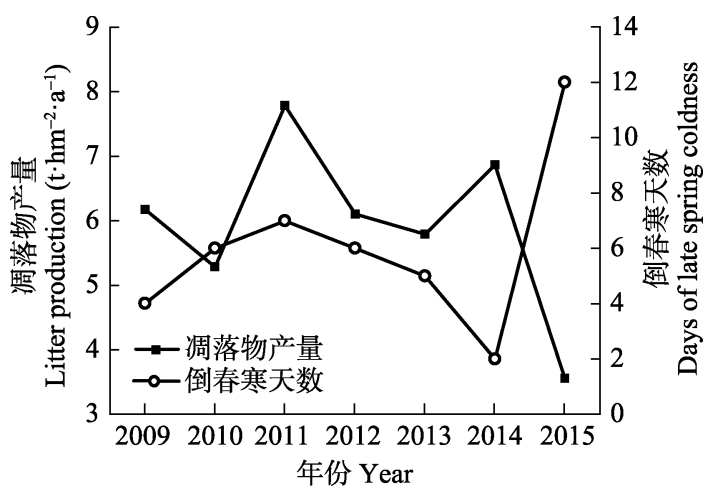

图2 2009-2015年调落物产量与倒春寒天数的关系。凋落物 产量数据点是 13 个调落物收集框的年平均值。

Fig. 2 The relationship of litter production and the number of late spring coldness days from 2009 to 2015 . Every point of litter production is the average annual value of the mass in 13 litter traps.
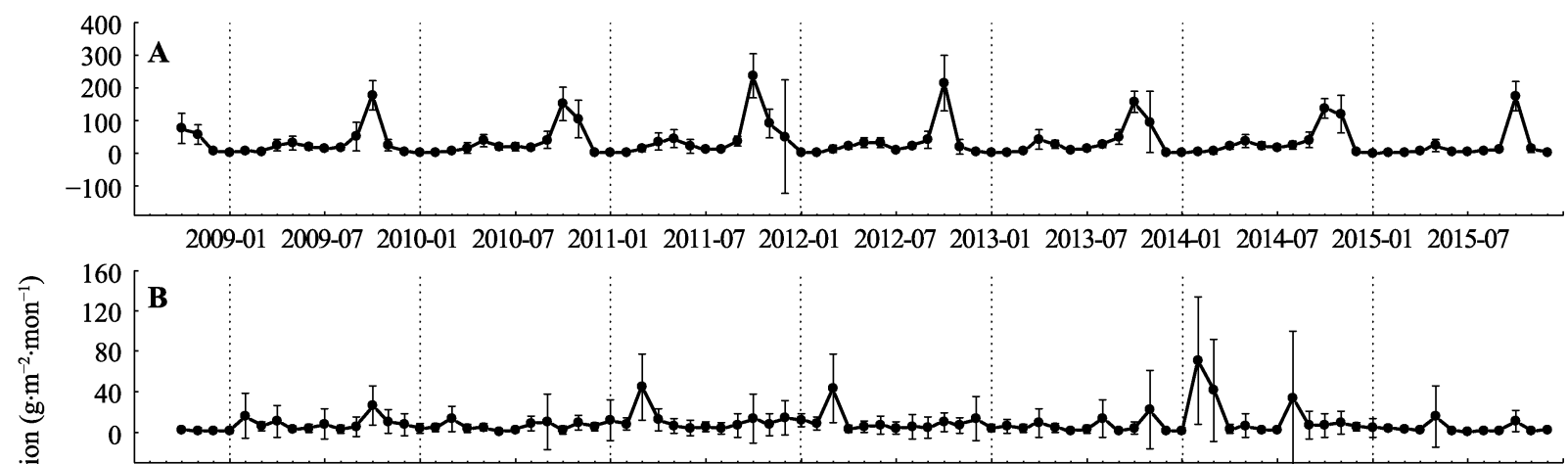

2009-01 2009-07 2010-01 2010-07 2011-01 2011-07 2012-01 2012-07 2013-01 2013-07 2014-01 2014-07 2015-01 2015-07
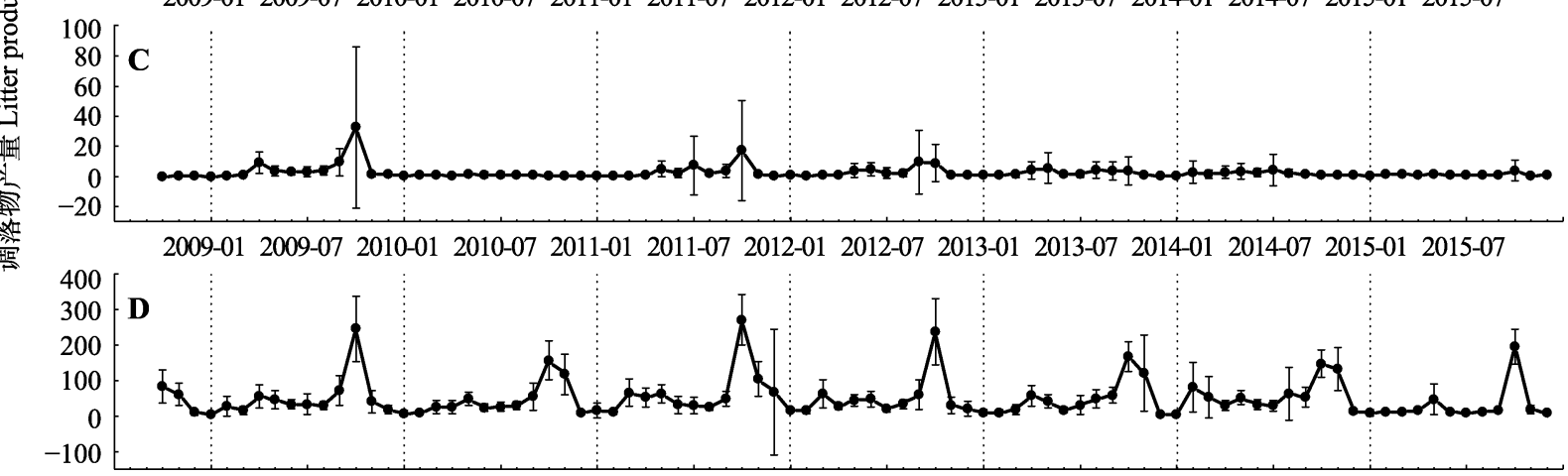

2009-01 2009-07 2010-01 2010-07 2011-01 2011-07 2012-01 2012-07 2013-01 2013-07 2014-01 2014-07 2015-01 2015-07

日期 Date (year-month)

图3 2009-2015年不同组分的调落物产量的年内动态变化(平均值沶准偏差)。每一个数据点是13个调落物收集框的月平均 值。A、B、C、D分别表示调落叶、调落枝、繁殖器官调落物和总调落物。

Fig. 3 The intra-annual dynamics of different composition of litter production from 2009 to 2015 (mean $\pm S D$ ). Every point of litter production is the average monthly value of the mass in 13 litter traps. A, B, C, and $\mathbf{D}$ denote leaf litter, twig litter, reproductive organ litter and total litter, respectively. 


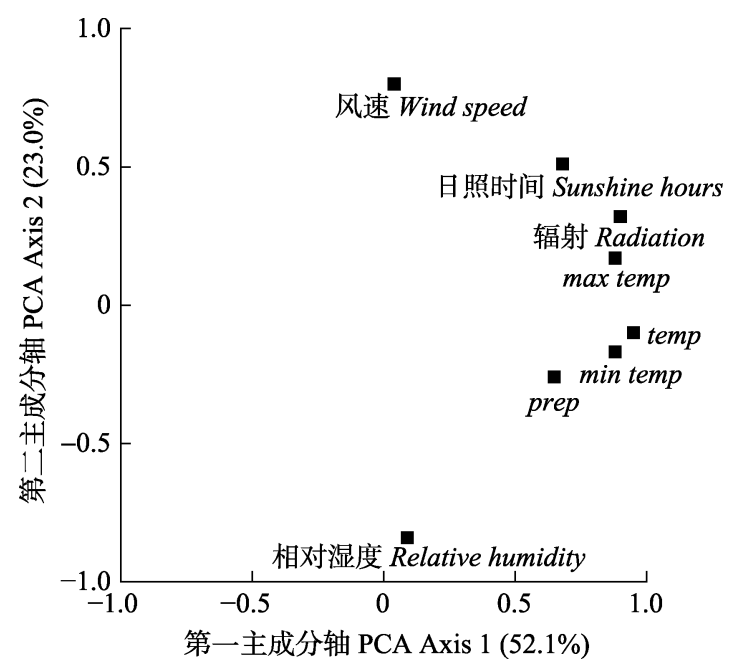

图4 2008-2015年8个气候变量月值的主成分分析结果。每 个点的横纵坐标为该变量在主成分轴上的荷载值, 百分数 表示方差被该主成分轴所解释的部分。“prep”表示月降水量, “temp" “max temp” “min temp"分别表示月平均气温、月最高 气温及月最低气温。

Fig. 4 Principal component analysis of the monthly values for eight meteorological variables from January 2008 to December 2015. The factor loadings of variables for the first two components are shown (the percentages are the variance explained by each axis). "prep" stands for monthly precipitation and "temp", "max temp", "min temp" stands for monthly average air temperature, monthly maximum air temperature and monthly minimum air temperature respectively.

成分主要描述了月平均风速与月平均相对湿度两个 气象变量的特征, 其相关系数 $r=-0.58(n=96, p<$ $0.001)$ 。在两个主成分中, 主成分与气象变量的系数 最大的分别为月平均温度和月平均相对湿度。

调落物总产量及各组分产量与月平均气温、月 平均相对湿度互相关分析显示, 调落物产量明显受 到平均气温及平均相对湿度的滞后影响, 且平均气 温影响更为显著(图5)。调落物总产量与当月的前第 1-4个月的月平均气温正相关，与当月的前第8-10 个月的月平均气温负相关; 调落叶产量受温度的滞 后影响与调落总量类似。调落物总产量与当月的前 第6-7及 10 个月的月平均相对湿度负相关; 调落叶 产量受相对湿度的滞后影响与调落总量相同。

7年的调落物季节性指数平均值为 0.032 (图6)。

Pearson相关分析表明, 调落物产量季节性指数与年 平均温度相关性显著, 相关系数 $r=0.77(n=7$, $p<0.05)$, 而与其他气象要素无显著相关关系 $(p>$ $0.05)$ 。

\section{3 调落物现存量年际动态}

7 年监测结果显示, 调落物现存量平均值为 $10.46 \mathrm{t} \cdot \mathrm{hm}^{-2} \cdot \mathrm{a}^{-1}, 2009-2014$ 年均保持在 $(11.41 \pm 0.92)$ $\mathrm{t} \cdot \mathrm{hm}^{-2} \cdot \mathrm{a}^{-1}$ 的水平上, 2015 年显著下降(图7)。调落物 现存量各组分含量大小 $\left(\mathrm{t} \cdot \mathrm{hm}^{-2} \cdot \mathrm{a}^{-1}\right)$ 与年产量各组分 含量大小存在部分差异, 杂物含量显著高于繁殖器 官、树皮及苔藓地衣，具体表现为叶(2.34-8.22)>枝 (1.65-3.33) >杂物 $(0.62-1.72)>$ 树皮 $(0.08-0.79)>$ 繁 殖器官 $(0.02-0.09)>$ 苔藓地衣 $(0.01-0.09)$ 。叶的现存 量动态与总量的现存量动态类似, 枝及其他组分的 调落物现存量在7年间基本保持稳定。Pearson相关 分析表明, 调落物产量与现存量相关性显著, 相关 系数 $r=0.35(n=91, p<0.001)$ 。

\section{3 讨论}

\section{1 前期不同阶段的气温影响常绿及落叶树种的 出叶落叶物候, 进而影响调落物产量}

本研究发现, 月平均气温对调落物产量季节动 态的滞后影响显著, 这与相关学者的研究结果 (Leuzinger et al., 2005; Estiarte \& Penuelas, 2015) 一 致。该森林生态系统由常绿树种和落叶树种混合组 成。不同生活型树种表现出具有差异的叶片性状、 调落格局以及物候对策, 这都是由生物对森林系统 内资源的不同利用方式所致(Devi \& Garkoti, 2013)。 常绿树种终年保持常绿, 没有明显的季相变化, 老 叶和新叶同存于树上，且老叶的脱落一年四季都在 进行, 但有两个较为明显的换叶高峰期, 分别出现 在春季3月下旬到 5 月上旬以及冬季 $11 、 12$ 月份。而 落叶树种的落叶期集中在9-11月, 在11月底至翌年 3 月期间为无叶期, 树木处于休眠状态。因此常绿和 落叶树种叶片调落对前期温度变化的响应也存在 差异。

常绿树种调落物总产量与当月的前第 1-4个月 的月平均气温正相关，主要因为生叶期间温度升高 会促进叶片生长。常绿阔叶树种在全年中一般有季 节性、间断性和持续性的抽枝出叶格局，因此在此 森林类型中常绿树种在一年中不同月份基本都存在 生叶现象。有研究发现, 出叶过程对大部分物种的 叶调落进程有重要影响(李心诚, 2014)。一般认为常 绿阔叶林所处生境的土壤较为贫㾑, 当植物从土壤 中获取的养分无法满足其营养需求时, 则会从其他 组织中转移储存的养分(Pasche et al., 2002)。叶片是 植物重要的营养库, 植物会优先从老叶中转移养分 促进新生枝叶的生长, 养分转移加速了叶片的衰老 以及部分老叶的调亡过程。出叶期间温度较高有利 

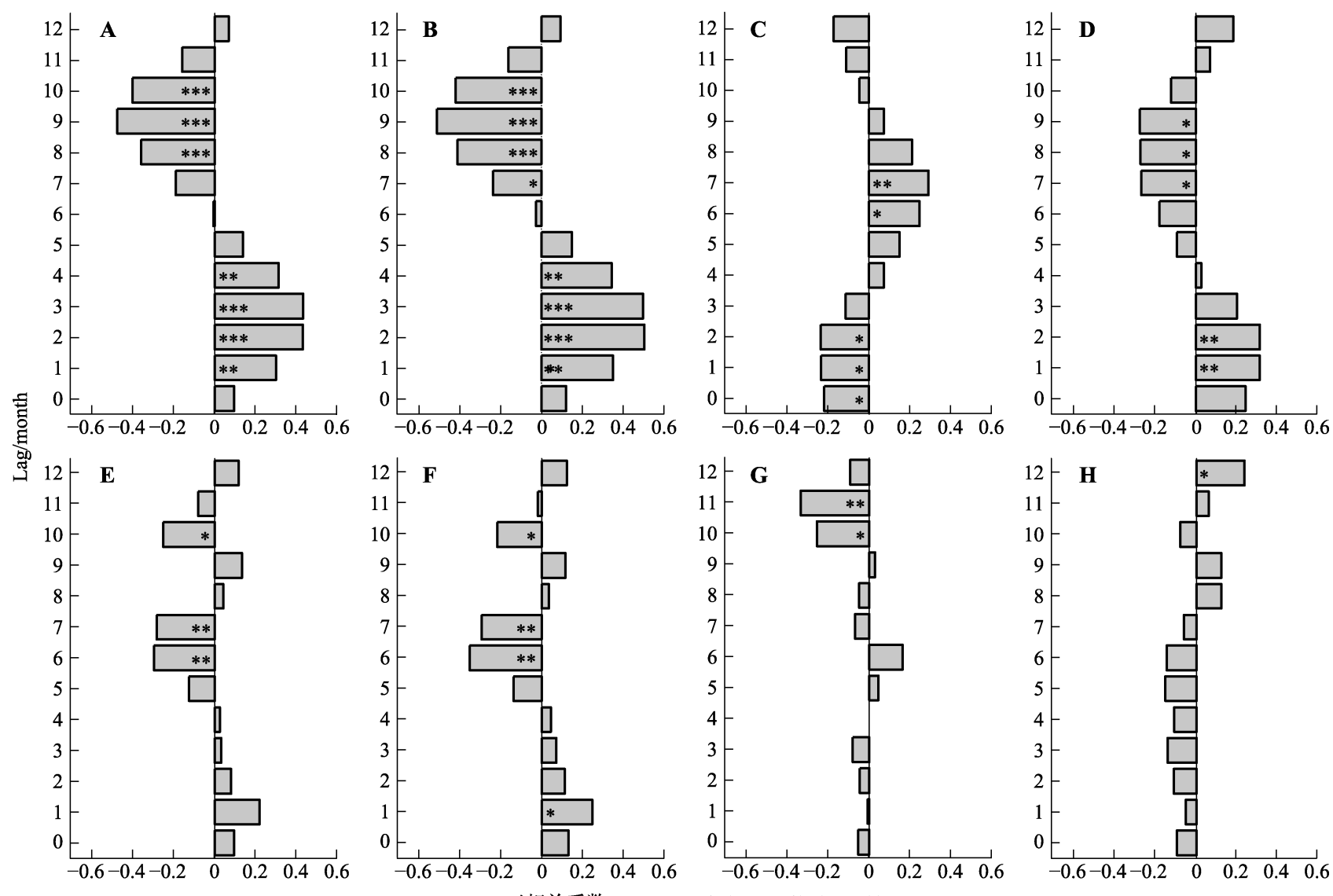

图5 月平均气温与调落物总产量 $(\mathbf{A}) 、$ 调落物叶产量 $(\mathbf{B}) 、$ 调落物枝产量 $(\mathbf{C})$ 及调落物繁殖器官产量 $(\mathbf{D})$ 的互相关系数和月平均 相对湿度与调落物总产量 $(\mathbf{E})$ 、调落物叶产量 $(\mathbf{F})$ 、调落物枝产量 $(\mathbf{G})$ 及调落物繁殖器官产量 $(\mathbf{H})$ 的互相关系数。调落物时间序 列落后于月平均气温和月平均相对湿度。 $n=87$ 。*, $p<0.05 ; * *, p<0.01 ; * * *, p<0.001$ 。

Fig. 5 Cross correlation coefficients for monthly total litter production (A), leaf litter production (B), branch litter production $(\mathbf{C})$ and reproductive organ litter production (D) as a function of monthly average air temperature and cross correlation coefficients for monthly total litter production (E), leaf litter production $(\mathbf{F})$, branch litter production $(\mathbf{G})$ and reproductive organ litter production $(\mathbf{H})$ as a function of monthly average relative humidity. For these analyses, the litter time series was lagged against monthly average air temperature and monthly average relative humidity. $n=87 .{ }^{*}, p<0.05 ; * *, p<0.01 ; * * *, p<0.001$.

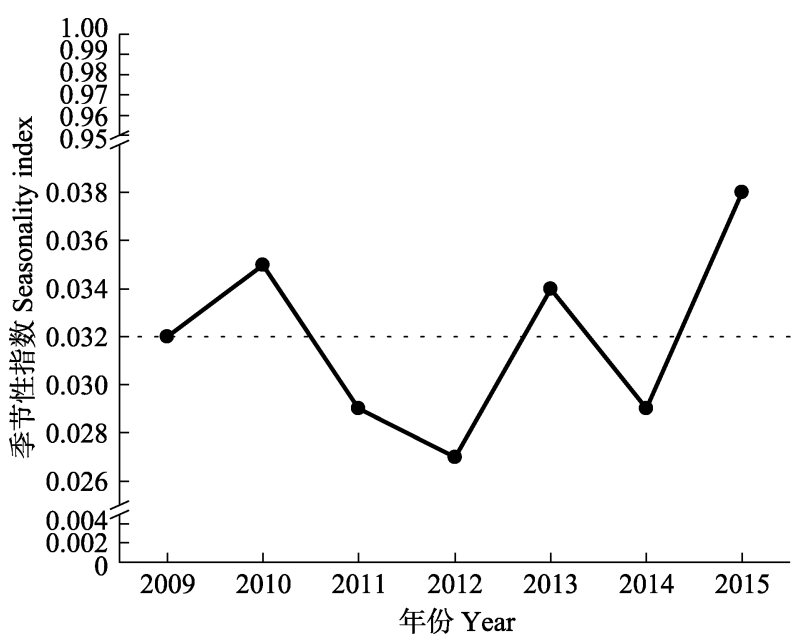

图6 2009-2015年的调落物产量季节性指数。虚线表示7年 调落物季节性指数的平均值。

Fig. 6 The seasonality index of litter production from 2009 to 2015. The dotted line represents the average value of seasonality index among seven years.

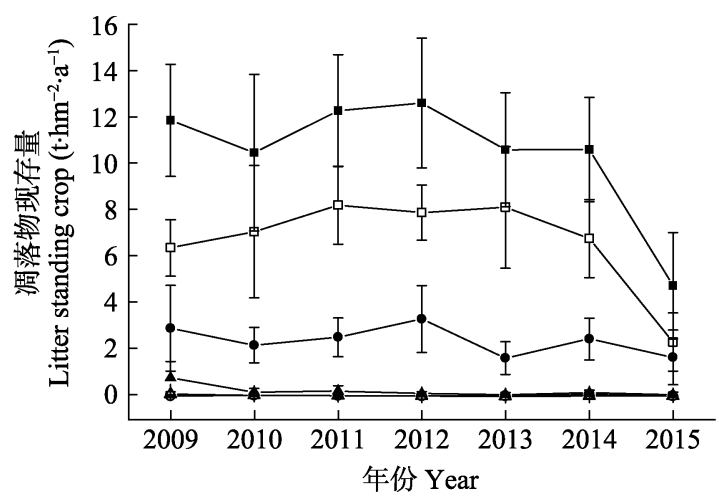

- 总量 Total litter - - 叶 Leaf $\rightarrow$ 枝 Branch

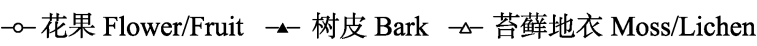

图 $72009-2015$ 年的调落物现存量年际动态变化(平均值 \pm 标准偏差)。每一个数据点是 13 个调落物现存量收集框的年 平均值。

Fig. 7 The dynamics of annual litter standing crop from 2009 to 2015 (mean $\pm S D$ ). Every point is the average annual value of the mass in 13 litter traps. 
于新叶的萌发(Devi \& Garkoti, 2013)。也有研究发现, 多数树种展叶始期受展叶前气温影响显著, 且在临 近展叶始期的月份, 气温影响更显著(许格希等, 2014)。新叶生长加速老叶的衰老及调落, 且植物落 叶动态相对于营养生长有时间滞后性(Milla et al., 2007), 因此常绿树种生叶期间气温升高会造成后 期凋落量增加。

落叶树种调落物总产量与当月的前第 1-4个月 的月平均气温正相关, 与当月的前第8-10个月的月 平均气温负相关, 主要因为其出叶与落叶期间对温 度变化的响应不同。总体来说, 温度升高会延迟叶 片衰老(Estiarte \& Penuelas, 2015), 如Jeong等(2011) 对北半球温带植被近 30 年的卫星观测发现, 随着温 度升高植物衰老延迟了 6.6 天。有研究发现, 叶寿命 与出叶时间和落叶时间显著关联(朱旭斌和孙书存, 2006), 因此延长落叶时间可以获得更长的叶寿命, 叶寿命的优化会使植物的碳获取最大化(Ackerly, 1999)。因此落叶树种落叶前气温较高可以在一定程 度上延缓落叶时间, 从而增加后期凋落物产量。而 落叶树种集中落叶前第7-10个月正值生叶期间, 温 度升高使植物出叶期提前。在物种水平上不同个体 之间, 早出叶的个体落叶较晚(Seiwa, 1999a, 1999b); 多个物种的比较研究发现, 早出叶的物种, 落叶迟 于其他物种(Ne'eman, 1993)。因此出叶阶段温度较 高会使得落叶时间延迟, 从而减少原来落叶时间的 调落量。但目前在群落水平上出叶物候与落叶物候 的关系尚不清晰, 如朱旭斌和孙书存(2006)在南京 地区对两处落叶林比较发现出叶时间与落叶时间之 间并没有显著关联。因此在群落水平上关于生叶期 间温度变化是否会对落叶物候产生影响仍需要进一 步探讨。

\section{2 夏季的相对湿度影响秋季叶片调落}

树木落叶物候除了受气温的滞后影响外, 干旱 也对其有重要影响。本研究发现调落物总产量与当 月的前第6-7及 10 个月的月平均相对湿度负相关。水 压是影响热带森林叶片调落的重要原因(Zhang et al., 2014), 当空气湿度较低, 叶片内部与外界存在 较大的气压差时, 植物为了避免过多的水分损失选 择使部分叶片调亡来减少对自身的损害, 如 Pedersen和Bille-Hansen (1999)发现常绿树种在夏季 干旱的年份会产生更多的调落物, 或者发生叶片提 前衰老调落的现象。但在亚热带地区, 秋季温度降
低导致叶片调落, 因此夏季干旱对落叶物候的影响 可能会被延后, 影响后期的调落物产量(Estiarte \& Penuelas, 2015)。也有研究发现, 夏季降水量的大小 会对秋季的叶片调落比例(Montserrat-Martí et al., 2009)及落叶时间(Gordo \& Sanz, 2010)产生影响。因 此在某种程度上, 空气相对湿度对后期凋落量的大 小存在滞后效应。但是长期的观测实验并没有发现 前期月降水量或干旱持续时间与叶片衰老调亡的时 间存在明显的相关关系(Estrella \& Menzel, 2006)。因 此关于相对湿度是否会对植物后期凋落量产生影响 以及其内在机制仍需要进一步的研究探讨。

\section{3 调落物产量季节性指数受群落整体落叶性影 响且与年平均气温显著相关}

该森林的调落物产量季节性指数较低, 原因是 此常绿落叶阔叶混交林中落叶树种相对于常绿树种 较多。Parsons等(2014)对澳大利亚热带雨林的研究 发现, 相对于其他变量, 森林落叶性对季节性指数 的影响最大, 如大部分分布在寒冷高地的常绿森林 季节性指数较高。这主要是因为落叶或半落叶的树 种之间存在不一致的叶片调落节律, 不同调落节律 的树种互相混杂造成了较为丰富的落叶格局 (Hyland et al., 2003), 使得整体群落水平上叶片调 落节律分布较为一致。而在常绿森林中, 叶片调落 节律在不同物种之间更趋于一致, 使得其凋落物季 节性指数较高。神农架地区典型植被常绿树种与落 叶树种的比例大致为 $1: 3$ (Ge et al., 2015), 因此其整 体凋落物季节性指数较低。

本研究发现凋落物产量季节性指数与年平均气 温显著正相关, 而Parsons等(2014)研究发现其与年 平均气温显著负相关, 这可能是由不同气候带内不 同物种的调落物候对温度的响应不同所致。Chave 等(2010)对南美洲81个热带森林研究发现降雨季节 性是影响热带森林调落物产量季节性的主要因素。 本研究发现年平均气温对调落物季节性指数影响显 著, 这对了解亚热带地区调落物季节性格局有重要 意义。

\section{4 调落物年产量、现存量及其年际动态}

该森林生态系统在2009-2015年的调落物平均 年产量为5.94 t $\cdot \mathrm{hm}^{-2}$, 介于亚热带森林生态系统调 落物产量的范围(3.00-11.00 t. $\left.\mathrm{hm}^{-2}\right)$ 内。与其他气候 带森林类型相比较发现, 该森林凋落物平均年产量 高于温带主要森林类型的调落物年产量, 低于热带 
表1 全球主要气候带森林调落物产量及现存量

Table 1 The litter production and standing crop of forests in the main climate zones around the world

\begin{tabular}{|c|c|c|c|c|}
\hline $\begin{array}{c}\text { 气候带 } \\
\text { Climate zone }\end{array}$ & $\begin{array}{l}\text { 森林类型 } \\
\text { Forest type }\end{array}$ & $\begin{array}{c}\text { 调落物产量 } \\
\text { Litter production }\left(\mathrm{t} \cdot \mathrm{hm}^{-2} \cdot \mathrm{a}^{-1}\right)\end{array}$ & $\begin{array}{c}\text { 调落物现存量 } \\
\text { Litter standing } \operatorname{crop}\left(\mathrm{t} \cdot \mathrm{hm}^{-2} \cdot \mathrm{a}^{-1}\right)\end{array}$ & $\begin{array}{l}\text { 参考文献 } \\
\text { Reference }\end{array}$ \\
\hline \multirow{6}{*}{$\begin{array}{c}\text { 热带 } \\
\text { Tropics }\end{array}$} & 亚马孙半落叶森林 & $8-10.5$ & $5-8$ & Sanches et al., 2008 \\
\hline & Semideciduous forests in Amazon Basin & & & \\
\hline & 澳大利亚北部热带雨林 & $5.44-11.29$ & $3.7-10.94$ & Parsons et al., 2014 \\
\hline & Tropical rain forests in northern Australia & & & \\
\hline & 中国台湾南部常绿阔叶林 & $6.98-9.13$ & & Liao et al., 2006 \\
\hline & $\begin{array}{l}\text { The evergreen broadleaved forest in } \\
\text { southern Taiwan, China }\end{array}$ & & & \\
\hline \multirow{8}{*}{$\begin{array}{c}\text { 亚热带 } \\
\text { Subtropics }\end{array}$} & 巴西巴拉那州半落叶森林 & $7.17-9.33$ & & Gonçalves Toscan et \\
\hline & Semideciduous forests in Parana, Brazil & & & al., 2014 \\
\hline & 中国鼎湖山常绿阔叶林 & $6.39-11.04$ & & Guan et al., 2004 \\
\hline & The evergreen broadleaved forest in Dinghu Mt., China & & & \\
\hline & 中国川西亚高山箭竹群落 & & $6.5-46.3$ & Qi et al., 2004 \\
\hline & Subalpine bamboo communities in western Sichuan, China & & & \\
\hline & 中国神农架常绿落叶阔叶混交林 & 5.94 & 10.46 & 本研究 \\
\hline & $\begin{array}{l}\text { The evergreen deciduous broadleaved } \\
\text { mixed forest in Shennongjia, China }\end{array}$ & & & This research \\
\hline \multirow{8}{*}{$\begin{array}{c}\text { 温带 } \\
\text { Temperate } \\
\text { zone }\end{array}$} & 中国长白山针阔混交林 & $3.15-5.12$ & & Li et al., 2010 \\
\hline & $\begin{array}{l}\text { Coniferous broadleaved mixed forests in } \\
\text { Changbai Mountain, China }\end{array}$ & & & \\
\hline & 中国东北主要森林类型 & $2.34-4.15$ & & Zhang et al., 2008 \\
\hline & The main forest types in northeastern China & & & \\
\hline & 巴西东南部大西洋沿岸次生林 & 5.7 & & Ferreira et al., 2014 \\
\hline & The secondary Atlantic forest in southeastern Brazil & & & \\
\hline & 中国辽宁油松蒙古栎林 & & 11.13 & Cui \& Chan, 2008 \\
\hline & $\begin{array}{l}\text { The forest of Quercus mongolica and Pinus } \\
\text { koraiensis in Liaoning, China }\end{array}$ & & & \\
\hline
\end{tabular}

森林群落整体调落物年产量(表1)。这说明受纬度影 响, 不同气候带间水热条件发生变化, 进而影响年 调落量(Adame et al., 2013)。与相同气候带内不同森 林类型比较也有区别, 这说明不同森林类型调落物 产量也存在显著差异(张新平等, 2008)。

调落物平均年现存量为 $10.46 \mathrm{t} \cdot \mathrm{hm}^{-2}$, 显著低 于中国亚热带调落物现存量平均水平 $28.44 \mathrm{t} \cdot \mathrm{hm}^{-2}$ (郑路和卢立华, 2012)。调落物现存量的多少受林 龄、林分密度、气候和物候因子影响(逯军峰等, 2007)。在一定时间内, 调落物现存量和林龄基本呈 现正相关关系, 即随着林龄增大, 调落物现存量增 加; 当到达一定林龄后, 林地内植物种类增多, 尤 其是阔叶树种类和数量的增多, 加快了调落物分解 的速率，此时调落物现存量开始下降。此样地为处 于顶极演替阶段的成熟林, 群落结构复杂, 人为干 扰少，因此可能造成该生态系统养分循环利用率较 高, 使得其凋落物现存量较低。此外, 不同的林分密 度和环境条件影响也可能造成该森林调落物现存量 与其他地区存在显著差异。
调落物产量及现存量的年际动态在2009-2014 年无明显变化, 而2015年均呈现显著降低，这是因 为该森林群落已进入顶极演替阶段, 且调落物产量 变化还会受到特定物候期内的气候变化及气候灾害 的影响。4月份正值常绿及落叶树种出叶期, 甚至某 些物种会选择早出叶来保证叶片以较高的光合效率 进行碳获取(朱旭斌和孙书存，2006)，而2015年4月 长达 12 天的倒春寒现象使得新生的嫩叶遭受到严重 的冻害, 从而大幅度减少当年的凋落物产量, 进而 影响调落物现存量。

\section{4 结论}

本研究分析了神农架常绿落叶阔叶混交林调落 物 7年间的动态特征，研究发现：该森林生态系统 调落物产量及现存量前期无明显年际变化趋势, 主 要与其所处演替阶段有关，而后期 4 月份发生的较 长时间的倒春寒现象会使当年的调落物产量及现存 量显著降低; 月平均气温和月平均相对湿度对调落 物产量季节动态的影响有滞后性，且平均气温的影 
响更加显著, 这主要因为树木出叶与落叶物候均受 前期温度变化的影响; 该森林调落物产量季节性指 数较低, 因为落叶树种相对常绿树种占优势, 且其 动态变化主要受年平均气温的影响。

致谢 感谢湖北神农架森林生态系统国家野外科学 观测研究站工作人员赵凯明、常超以及习新强在野 外监测和室内分析中给予的帮助。

\section{参考文献}

Ackerly D (1999). Self-shading, carbon gain and leaf dynamics: A test of alternative optimality models. Oecologia, 119, 300-310.

Adame MF, Zaldívar-Jimenez A, Teutli C, Caamal JP, Andueza MT, López-Adame H, Cano R, Hernández-Arana HA, Torres-Lara R, Herrera-Silveira JA (2013). Drivers of mangrove litterfall within a karstic region affected by frequent hurricanes. Biotropica, 45, 147-154.

Aguilos MM, Takagi K, Takahashi H, Hasegawa J, Ashiya D, Kotsuka C, Naniwa A, Sakai R, Ito K, Miyoshi C (2012). Enhanced annual litterfall production due to spring solar radiation in cool-temperate mixed forests of northern Hokkaido, Japan. Journal of Agricultural Meteorology, 68, 215-224.

Caritat A, García-Berthou E, Lapeña R, Vilar L (2006). Litter production in a Quercus suber forest of Montseny (NE Spain) and its relationship to meteorological conditions. Annals of Forest Science, 63, 791-800.

Chave J, Navarrete D, Almeida S, Álvarez E, Aragão L, Bonal D, Châtelet P, Silva-Espejo JE, Goret JY, von Hildebrand P, Jiménez E, Patiño S, Peñuela MC, Phillips OL, Stevenson P, Malhi Y (2010). Regional and seasonal patterns of litterfall in tropical south America. Biogeosciences, 7, 43-55.

Cui JG, Chan J (2008). Studying litter standing crop of Quercus mongolica and Pinus koraiensis in west of Liaoning. Research of Soil and Water Conservation, 15, 154-155, 158. [崔建国, 镡娟 (2008). 辽西油松蒙古栎林下凋落物现 存量及持水能力的研究. 水土保持研究, 15, 154-155, 158.]

DeForest JL, Chen J, McNulty SG (2009). Leaf litter is an important mediator of soil respiration in an oak-dominated forest. International Journal of Biometeorology, 53, 127134.

Devi AF, Garkoti S (2013). Variation in evergreen and deciduous species leaf phenology in Assam, India. Trees, 27, 985-997.

Estiarte M, Penuelas J (2015). Alteration of the phenology of leaf senescence and fall in winter deciduous species by climate change: Effects on nutrient proficiency. Global Change Biology, 21, 1005-1017.

Estrella N, Menzel A (2006). Responses of leaf colouring in four deciduous tree species to climate and weather in
Germany. Climate Research, 32, 253-267.

Facelli JM, Pickett STA (1991). Plant litter: Its dynamics and effects on plant community structure. Botanical Review, 57, 1-32.

Ferreira ML, Silva JL, Pereira EE, do Nascimento LamanoFerreira AP (2014). Litter fall production and decomposition in a fragment of secondary Atlantic forest of São Paulo, SP, southeastern Brazil. Revista Árvore, 38, 591600.

Ge JL, Xiong GM, Wang ZX, Zhang M, Zhao CM, Shen GZ, Xu WT, Xie ZQ (2015). Altered dynamics of broad-leaved tree species in a Chinese subtropical montane mixed forest: The role of an anomalous extreme 2008 ice storm episode. Ecology and Evolution, 5, 1484-1493.

Gonçalves Toscan MA, Temponi LG, Bittencourt Guimarães AT, Cândido Junior JF (2014). Litter production and seed rain in semideciduous forest fragments at different successional stages in the western part of the state of Paraná, Brazil. Acta Botanica Brasilica, 28, 392-403.

Gordo O, Sanz JJ (2010) Impact of climate change on plant phenology in Mediterranean ecosystems. Global Change Biology, 16, 1082-1106.

Guang LL, Zhou GY, Zhang DQ, Liu JX, Zhang QM (2004). Twenty years of litter fall dynamics in subtropical evergreen broad-leaved forests at the Dinghushan forest ecosystem research station. Acta Phytoecologica Sinica, 28, 449-456. [官丽莉, 周国逸, 张德强, 刘菊秀, 张倩媚 (2004). 鼎湖山南亚热带常绿阔叶林调落物量20年动态 研究. 植物生态学报, 28, 449-456.]

Huang YT (2016). The Functional Community Structure and Its Dynamics of the Subtropical Evergreen-Deciduous Broadleaved Mixed Forest in Southwest Hubei of Central China. $\mathrm{PhD}$ dissertation, Chinese Academy of Forestry, Beijing. [黄永涛 (2016). 亚热带常绿落叶阔叶混交林的功 能性群落结构及其动态研究. 博士学位论文, 中国林业 科学研究院, 北京.]

Hyland B, Whiffin T, Christophel D, Gray B, Elick R (2003). Australian Tropical Rain Forest Plants-Trees, Shrubs and Vines. CSIRO, Melbourne.

Janssens IA, Pilegaard K (2003). Large seasonal changes in $Q_{10}$ of soil respiration in a beech forest. Global Change Biology, 9, 911-918.

Jeong SJ, Ho CH, Gim HJ, Brown ME (2011). Phenology shifts at start vs. end of growing season in temperate vegetation over the Northern Hemisphere for the period 1982-2008. Global Change Biology, 17, 2385-2399.

Leuzinger S, Zotz G, Asshoff R, Körner C (2005). Responses of deciduous forest trees to severe drought in central Europe. Tree Physiology, 25, 641-650.

Li X, Hu Y, Han S, Liu Y, Zhang Y (2010). Litterfall and litter chemistry change over time in an old-growth temperate forest, northeastern China. Annals of Forest Science, 67, 206. DOI: $10.1051 /$ forest/2009099.

Li XC (2014). Litterfall Phenology and Patterns of 22 Evergreen Woody Species in Subtropical Evergreen Forest in 
Tiantong Zhejiang, China. Master degree dissertation, Zhejiang Normal University, Jinhua, Zhejiang. [李心诚 (2014). 浙江天童常绿阔叶林 22 种常绿木本植物全年落 叶物候及其格局. 硕士学位论文, 浙江师范大学, 浙江 金华.]

Liao JH, Wang HH, Tsai CC, Hseu ZY (2006). Litter production, decomposition and nutrient return of uplifted coral reef tropical forest. Forest Ecology and Management, 235, 174-185.

Lu JF, Wang H, Cao J, Yuan HB (2007). Water holding capacity and nutrients of litter layers in a Pinus tabulaeformis plantation at different ages in Mount Xiaolong of Gansu. Journal of Zhejiang Forestry College, 24, 319-325. [逯军 峰, 王辉, 曹靖, 袁宏波 (2007). 不同林龄油松人工林 枯枝落叶层持水性及养分含量. 浙江林学院学报, 24 , 319-325.]

Ma MZ, Shen GZ, Xiong GM, Zhao CM, Xu WT, Zhou YB, Xie ZQ (2017). Characteristic and representativeness of the vertical vegetation zonation along the altitudinal gradient in Shennongjia Natural Heritage. Chinese Journal of Plant Ecology, 41，1127-1139. [马明哲, 申国珍, 熊高 明, 赵常明, 徐文婷, 周友兵, 谢宗强 (2017). 神农架 自然遗产地植被垂直带谱的特点和代表性. 植物生态 学报, 41, 1127-1139.]

Milla R, Palacio S, Maestro-Martinez M, Montserrat-Marti G (2007). Leaf exchange in a mediterranean shrub: Water, nutrient, non-structural carbohydrate and osmolyte dynamics. Tree Physiology, 27, 951-960.

Montserrat-Martí G, Camarero JJ, Palacio S, Pérez-Rontomé C, Milla R, Albuixech J, Maestro M (2009). Summer-drought constrains the phenology and growth of two coexisting mediterranean oaks with contrasting leaf habit: Implications for their persistence and reproduction. Trees, 23, 787-799.

Ne'eman G (1993). Variation in leaf phenology and habitat in Quercus thubuensis, a Mediterranean deciduous tree. Journal of Ecology, 81, 627-634.

Parsons SA, Valdez-Ramirez V, Congdon RA, Williams SE (2014). Contrasting patterns of litterfall seasonality and seasonal changes in litter decomposability in a tropical rainforest region. Biogeosciences, 11, 5047-5056.

Pasche F, Pornon A, Lamaze T (2002). Do mature leaves provide a net source of nitrogen supporting shoot growth in Rhododendron ferrugineum? New Phytologist, 154, 99-105.

Pedersen LB, Bille-Hansen J (1999). A comparison of litterfall and element fluxes in even aged Norway spruce, sitka spruce and beech stands in Denmark. Forest Ecology and Management, 114, 55-70.

Qi ZM, Wang KY, Song GY, Yang WQ (2004). Bio-chemical properties of the forest floor in subalpine bamboo communities in western Sichuan. Acta Ecologica Sinica, 24, 1230-1236. [齐泽民, 王开运，宋光显，杨万勤 (2004). 川西亚高山箭竹群落枯枝落叶层生物化学特性. 生态 学报, 24, 1230-1236.]

www.plant-ecology.com
Sanches L, Abido Valentini CM, Pinto Júnior OB, Nogueira JS, Vourlitis GL, Biudes MS, da Silva CJ, Bambi P, Lobo FA (2008). Seasonal and interannual litter dynamics of a tropical semideciduous forest of the southern Amazon Basin, Brazil. Journal of Geophysical Research-Biogeosciences, 113, G04007. DOI: 10.1029/2007JG000593.

Seiwa K (1999a). Changes in leaf phenology are dependent on tree height in Acer mono, a deciduous broad-leaved tree. Annuals of Botany, 83, 355-361.

Seiwa K (1999b). Ontogenetic changes in leaf phenology of Ulmus davidiana var. Japonica, a deciduous broad-leaved tree. Tree Physiology, 19, 793-797.

Wu QQ, Wang CK, Zhang QZ (2017). Inter and intra-annual dynamics in litter production for six temperate forests. Acta Ecologica Sinica, 37, 760-769. [武启骞, 王传宽, 张全智 (2017). 6种温带森林调落量年际及年内动态. 生态学报, 37, 760-769.]

Xu GX, Luo SX, Guo QS, Pei SX, Shi ZM, Zhu L, Zhu NN (2014). Responses of leaf unfolding and flowering to climate change in 12 tropical evergreen broadleaf tree species in Jianfengling, Hainan Island. Chinese Journal of Plant Ecology, 38，585-598. [许格希，罗水兴，郭泉水， 裴顺祥, 史作民, 朱莉, 朱妮妮 (2014). 海南岛尖峰岭 12 种热带常绿阔叶乔木展叶期与开花期对气候变化的 响应. 植物生态学报, 38, 585-598.]

Zhang HC, Yuan WP, Dong WJ, Liu SG (2014). Seasonal patterns of litterfall in forest ecosystem worldwide. Ecological Complexity, 20, 240-247.

Zhang XP, Wang XP, Zhu B, Zong ZJ, Peng CH, Fang JY (2008). Litter fall production in relation to enviromental factors in northeast China's forests. Journal of Plant Ecology (Chinese Version), 32, 1031-1040. [张新平, 王 襄平, 朱彪, 宗占江, 彭长辉, 方精云 (2008). 我国东 北主要森林类型的调落物产量及其影响因素. 植物生 态学报, 32, 1031-1040.]

Zheng L, Lu LH (2012). Standing crop and nutrient characteristics of forest floor litter in China. Journal of Northwest Forestry University, 27(1), 63-69. [郑路, 卢立华 (2012). 我国森林地表调落物现存量及养分特征. 西北林学院 学报, 27(1), 63-69.]

Zheng Z, Li YR, Liu HM, Feng ZL, Gan JM, Kong WJ (2005). Litterfall of tropical rain forests at different altitudes, Xishuangbanna, southwest China. Acta Phytoecologica Sinica，29，18-27. [郑征, 李佑荣, 刘宏茂, 冯志立, 甘 建民, 孔维静 (2005). 西双版纳不同海拔热带雨林调落 量变化研究. 植物生态学报, 29, 18-27.]

Zhu XB, Sun SC (2006). Leaf phenology of woody species in deciduous broad-leaved oak forests in Nanjing area, east China. Journal of Plant Ecology, 30, 25-32. [朱旭斌, 孙 书存 (2006). 南京地区落叶栋林木本植物叶物候研究. 植物生态学报, 30, 25-32.]

特邀编委: 陈 槐 责任编辑: 李 敏 